\title{
BMJ Open Epidemiology, quality and reporting characteristics of meta-analyses of observational studies published in Chinese journals
}

\author{
Zhe-wen Zhang, ${ }^{1}$ Juan Cheng, ${ }^{2}$ Zhuan Liu, ${ }^{1}$ Ji-chun Ma, ${ }^{3}$ Jin-long Li, ${ }^{3}$ Jing Wang, ${ }^{3}$ \\ Ke-hu Yang ${ }^{4}$
}

To cite: Zhang Z-wen, Cheng J, Liu Z, et al. Epidemiology, quality and reporting characteristics of meta-analyses of observational studies published in Chinese journals. BMJ Open 2015;5: e008066. doi:10.1136/ bmjopen-2015-008066

- Prepublication history and additional material is available. To view please visit the journal (http://dx.doi.org/ 10.1136/bmjopen-2015008066).

Z-WZ and JC contributed equally to this work.

Received 2 March 2015 Revised 10 November 2015 Accepted 13 November 2015

CrossMark

For numbered affiliations see end of article.

Correspondence to

Ke-hu Yang;

yebm123@163.com

\section{ABSTRACT}

Objective: The aim of this study was to examine the epidemiological and reporting characteristics as well as the methodological quality of meta-analyses (MAs) of observational studies published in Chinese journals.

Methods: 5 Chinese databases were searched for MAs of observational studies published from January 1978 to May 2014. Data were extracted into Excel spreadsheets, and Meta-analysis of Observational Studies in Epidemiology (MOOSE) and Assessment of Multiple Systematic Reviews (AMSTAR) checklists were used to assess reporting characteristics and methodological quality, respectively.

Results: A total of 607 MAs were included. Only $52.2 \%$ of the MAs assessed the quality of the included primary studies, and the retrieval information was not comprehensive in more than half $(85.8 \%)$ of the MAs. In addition, $50(8.2 \%)$ MAs did not search any Chinese databases, while $126(20.8 \%)$ studies did not search any English databases. Approximately $41.2 \%$ of the MAs did not describe the statistical methods in sufficient details, and most (95.5\%) MAs did not report on conflicts of interest. However, compared with the before publication of the MOOSE Checklist, the quality of reporting improved significantly for 20 subitems after publication of the MOOSE Checklist, and 7 items of the included MAs demonstrated significant improvement after publication of the AMSTAR Checklist $(\mathrm{p}<0.05)$.

Conclusions: Although many MAs of observational studies have been published in Chinese journals, the reporting quality is questionable. Thus, there is an urgent need to increase the use of reporting guidelines and methodological tools in China; we recommend that Chinese journals adopt the MOOSE and AMSTAR criteria.

\section{INTRODUCTION}

Meta-analysis as a statistical and scientific tool has grown immensely popular over the past decade. ${ }^{1}$ Several studies have considered that meta-analyses including only randomised

\section{Strengths and limitations of this study}

- Our study was the first to examine the compliance of Chinese observational study meta-analyses using the Meta-analysis of Observational Studies in Epidemiology reporting guidelines and the Assessment of Multiple Systematic Reviews tool for assessing methodological quality.

- This study included a comprehensive literature search using five Chinese databases to ensure a high degree of representativeness.

- In addition, this study included only meta-analyses published in Chinese journals, whereas Chinese investigators increasingly publish articles in international journals.

controlled trials (RCTs) would provide stronger evidence than those not including RCTs. ${ }^{2}{ }^{3}$ However, in many situations, randomised controlled designs are not feasible and only data from observational studies are available. Therefore, observational studies have an important role in answering questions related to treatment effectiveness and disease aetiology.

Owing to the lack of randomisation, observational studies are inherently more prone to potential biases. ${ }^{45}$ For instance, case-control studies are always retrospective in nature, which increases the potential for incomplete and biased data collection. Therefore, it is more important to describe exactly the methodology that led to the generation of results from meta-analyses of observational studies.

The Meta-Analysis of Observational Studies in Epidemiology (MOOSE) checklist and the Assessment of Multiple Systematic Reviews (AMSTAR) tool were first introduced and published in China in 2010. ${ }^{6}{ }^{7}$ Over the past decades, many studies have described the quality and reporting characteristics in 
multidisciplinary clinical research topics, but these studies did not include information about epidemiological characteristics or methodological quality based on the meta-analyses of observational studies in China. ${ }^{8-10}$ The aim of this study is to describe the epidemiological and reporting characteristics, as well as the methodological quality, of the meta-analyses of observational studies published in Chinese journals, using the most up-to-date assessment tools.

\section{METHODS}

\section{Data sources and searches}

Five Chinese databases (Chinese Biomedical Literature database (CBM), Chinese Science Citation Database (CSCD), VIP information (Chinese Scientific Journals database), China National Knowledge Infrastructure (CNKI) and WANFANG database (Chinese Medicine Premier)), were searched from inception through May 2014 (see online supplementary file 1). The search terms included 'review', 'meta-analysis', 'systematic review', 'pooled analysis', 'overview', 'cohort', 'case control' and 'cross sectional'. The search was limited to the following criteria: MAs of the article type and one of three main study designs, including cohort, case-control and cross-sectional. The search was limited to human studies. Editorials, letters, conferences and meeting abstracts were excluded. Then, the full texts of the potentially eligible studies were retrieved and further evaluated. The references of retrieved articles were also searched.

\section{Data collection and analysis}

Study reports were grouped according to the year that the two checklists were introduced in China: 2009 and earlier (prepublication) or 2010-2014 (postpublication). Articles were scored as 'yes' if they were reported in enough detail to allow the reader to judge that the definition had been met. An article was scored as "partially/cannot tell' only when the report was incomplete or unclear. Articles were coded as 'no' when the checklist item was not reported. We also collected information regarding the risk of bias tools and methods used to search Chinese journals.

To enhance the reviewers' inter-rater agreement, we evaluated 20 papers (not included in the study sample) in a pilot test of the database prior to starting the data abstraction process. Proper scoring of each item in the database was discussed in detail. The Preferred Reporting Items for Systematic reviews and Meta-Analyses (PRISMA) guideline was also followed (see online supplementary file 2). Z-wZ and JC searched the literature. ZL, J-cM JC, J-IL and JW participated in data extraction and quality assessment of the MAs, with guidance from K-hY. Intraclass correlation coefficients (ICCs) were used to assess inter-rater reliability within each item. ${ }^{11}$ The $\chi^{2}$ test was used to compare the quality of MAs published in journals cited by CSCD and
non-CSCD. Statistical significance was considered when $\mathrm{p}<0.05$. Data analysis was performed with SPSS V.13.0.

\section{RESULTS}

Search

A total of 2930 potentially relevant reports from the databases were identified for review. The screening process excluded 1977 reviews due to duplication or the absence of MAs. Another 346 reviews that were not MAs of observational studies were excluded after examination of the full texts. Finally, a total of 607 MAs were considered to be eligible for our study (figure 1 and online supplementary file 3 ).

\section{Descriptive characteristics}

The first related methods of MAs concerning observational studies were published in China in 1995, and the overall number of published MAs has subsequently increased. The 607 MAs included were published in 265 different Chinese journals. Less than one-third (28.5\%) of the MAs were supported by the government. The most common conditions studied included diseases of neoplasms $(43 \%)$ and the circulatory system (17\%). The number of authors ranged from 1 to 11 with a median of four authors. Less than one-fifth $(18.9 \%)$ of the MAs were cited by the CSCD. In addition, $85 \%$ of the articles included the term 'meta-analyses' in the title. None of the MAs had been updated from a previous review (table 1).

\section{Risk of bias instruments}

Only $52.2 \%$ of the MAs reported that they assessed the quality of the included primary studies. Of these, 39 (6.3\%) MAs used the Newcastle-Ottawa scale (NOS); 19 (3.1\%) MAs used the critical appraisal skill programme (CASP); 12 (2\%) MAs used the Cochrane Collaboration scale (CC); $29(4.8 \%)$ MAs used the Strengthening the Reporting of Observational Studies in Epidemiology

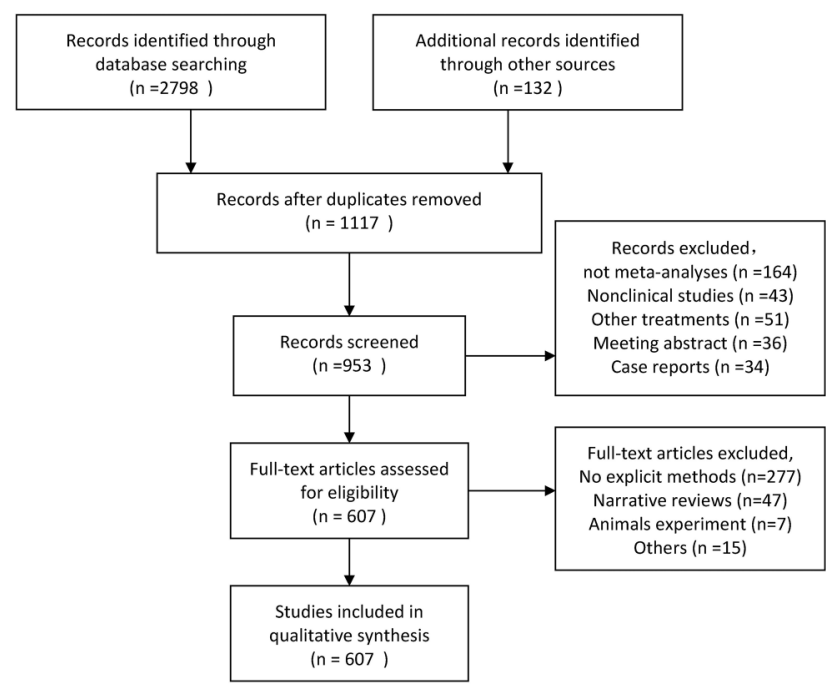

Figure 1 Flow chart of systematic search. 
Table 1 Descriptive characteristics of included MAs

\begin{tabular}{|c|c|}
\hline Category & All meta-analyses $\mathrm{n}=607$ \\
\hline Total number of journals & 265 \\
\hline \multicolumn{2}{|l|}{ Funding source (yes) } \\
\hline Government & $173(28.5)$ \\
\hline Industrial & $0(0)$ \\
\hline Other & $39(6.3)$ \\
\hline \multicolumn{2}{|l|}{ Common ICD-10 } \\
\hline Neoplasms & $261(43)$ \\
\hline Diseases of the digestive system & $26(4.3)$ \\
\hline Certain infectious and parasitic diseases & $28(4.6)$ \\
\hline Disease of the circulatory system & $103(17)$ \\
\hline Diseases of the musculoskeletal system and connective tissue & $14(2.3)$ \\
\hline Diseases of the blood and blood forming organs and immune mechanism & $12(1.9)$ \\
\hline Endocrine, nutritional and metabolic diseases & $34(5.6)$ \\
\hline Diseases of the respiratory system & $16(2.6)$ \\
\hline Diseases of the genitourinary system & $14(2.3)$ \\
\hline Congenital malformations, deformations and chromosomal abnormalities & $3(0.5)$ \\
\hline Injury, poisoning and certain other consequences of external causes & $61(10.1)$ \\
\hline Pregnancy, childbirth and puerperium & $22(3.6)$ \\
\hline Certain conditions originating in the perinatal period & $6(0.9)$ \\
\hline Diseases of the eye and adnexa & $7(1.2)$ \\
\hline Number of authors, median (IQR) & $4(1-11)$ \\
\hline \multicolumn{2}{|l|}{ Number of included studies, median (IQR) } \\
\hline Cohort, n=24 & $13(2-215)$ \\
\hline Case-controlled, $n=488$ & $12(2-90)$ \\
\hline Cohort + case-controlled, $n=65$ & $11(1-189)$ \\
\hline Cross-sectional, $n=10$ & $16(2-63)$ \\
\hline \multicolumn{2}{|l|}{ Number of participants in included studies, median (IQR) } \\
\hline Cohort, $n=89$ & 561279 (76-7 069 228) \\
\hline Case-controlled, $n=553$ & $4575(72-105$ 293) \\
\hline Cross-sectional, $n=10$ & $78(3-11215)$ \\
\hline \multicolumn{2}{|l|}{ Types of clinical study (yes) } \\
\hline Therapy & $31(5.1)$ \\
\hline Aetiology & 576 (94.9) \\
\hline \multicolumn{2}{|l|}{ Types of models in included studies (yes) } \\
\hline Fixed model & $107(17.6)$ \\
\hline Random model & $164(27.2)$ \\
\hline Not reported & $336(55.2)$ \\
\hline Indexed in CSCD, yes n (\%) & 18.9 \\
\hline Update of a previous review: yes $\mathrm{n}(\%)$ & $0(0)$ \\
\hline
\end{tabular}

(STROBE); and 218 (36\%) MAs presented either the reference for the scale or used unnamed scales. Among the 607 included MAs, $548(90.3 \%)$ provided the name and version of the statistical software employed, including particulars of any special features used (table 2).

\section{Searching details for studies}

Within the included studies, the median number of databases used was 4 , with a range of 0 to 16 . Regarding the Chinese-language databases, the most commonly searched database was CNKI (65.7\%), followed by CBM $(51.7 \%)$ and VIP $(49.4 \%)$. PUBMED was the most commonly searched English-language database (66\%); the second most common database was EMBASE (28.7\%), followed by the Cochrane Library $(16.8 \%)$. A total of 50
Table 2 Tools of quality assessment in included meta-analyses

\begin{tabular}{lcc}
\hline Quality assessment & $\begin{array}{l}\text { Number (\%), } \\
\text { of } \mathbf{n = 6 0 7}\end{array}$ & $\mathbf{9 5 \%} \mathbf{C l}$ \\
\hline NOS & $39(6.3)$ & 4.7 to 8.7 \\
CASP & $19(3.1)$ & 2 to 4.9 \\
Cochrane scale & $12(2.0)$ & 1.1 to 3.4 \\
STROBE* & $29(4.8)$ & 3.3 to 6.8 \\
Others & $218(36.0)$ & 32.2 to 39.8 \\
Not reported/not performed & $290(47.8)$ & 43.8 to 51.8 \\
\hline${ }^{*}$ The STROBE was not a tool for assessing the quality of \\
published observational studies. \\
CASP, critical appraisal skill programme; NOS, Newcastle-Ottawa \\
scale; STROBE, Strengthening the Reporting of Observational \\
Studies in Epidemiology.
\end{tabular}


$(8.2 \%)$ MAs did not search any Chinese database, and $126(20.8 \%)$ MAs did not search any English language database. In addition, 559 (92.1\%) revealed the search terms (some terms given but not all), but only 87 $(14.3 \%)$ studies presented the search strategy (search terms and Boolean operators; table 3).

\section{AMSTAR checklist (current edition) assessment}

Table 4 shows the summary of results for the risk of bias of all MAs. Compliance with the AMSTAR checklist

\begin{tabular}{|c|c|}
\hline Assessment item & $\begin{array}{l}\text { Number } \\
(\%)\end{array}$ \\
\hline $\begin{array}{l}\text { Number of databases searched, median } \\
\text { (range) }\end{array}$ & $4(0-16)$ \\
\hline \multicolumn{2}{|l|}{ Chinese databases searched } \\
\hline $\begin{array}{l}\text { China National Knowledge Infrastructure } \\
\text { (CNKI) }\end{array}$ & $464(76.4)$ \\
\hline $\begin{array}{l}\text { Chinese Biomedical (CBM) literature } \\
\text { database }\end{array}$ & $314(51.7)$ \\
\hline $\begin{array}{l}\text { VIP information (Chinese Scientific } \\
\text { Journals database) }\end{array}$ & $300(49.4)$ \\
\hline $\begin{array}{l}\text { WANFANG database (Chinese Medicine } \\
\text { Premier) }\end{array}$ & $277(45.6)$ \\
\hline Others & $34(5.6)$ \\
\hline \multicolumn{2}{|l|}{ English-language databases searched } \\
\hline PubMed & $466(66)$ \\
\hline EMBASE & $174(28.7)$ \\
\hline Cochrane Library & $102(16.8)$ \\
\hline OVID & $58(9.6)$ \\
\hline SCl (Web OF Science) & $42(6.9)$ \\
\hline Springerlink & $39(6.4)$ \\
\hline Elsevier Science & $37(6.1)$ \\
\hline Others & $104(17.1)$ \\
\hline \multicolumn{2}{|l|}{ Number of Chinese databases } \\
\hline 0 & $50(8.2)$ \\
\hline 1 & $111(18.3)$ \\
\hline 2 & $156(25.7)$ \\
\hline 3 & $178(29.3)$ \\
\hline$>3$ & $112(18.5)$ \\
\hline \multicolumn{2}{|l|}{ Number of English databases } \\
\hline 0 & $126(20.8)$ \\
\hline 1 & $182(30)$ \\
\hline 2 & $157(25.9)$ \\
\hline 3 & $88(14.5)$ \\
\hline$>3$ & $54(8.8)$ \\
\hline \multicolumn{2}{|l|}{ Was the strategy given in full? } \\
\hline $\begin{array}{l}\text { Search strategy (search terms and Boolean } \\
\text { operators) }\end{array}$ & $87(14.3)$ \\
\hline Partial (eg, some terms given but not all) & $559(92.1)$ \\
\hline Not report & $15(2.5)$ \\
\hline \multicolumn{2}{|l|}{ Other resources searched } \\
\hline Reference sections of retrieve articles & $489(80.5)$ \\
\hline Conference abstracts/posters & $336(55.4)$ \\
\hline \multicolumn{2}{|l|}{ Assistant retrieval methods } \\
\hline $\begin{array}{l}\text { Manual searching (eg, reference, } \\
\text { conference) }\end{array}$ & $411(67.7)$ \\
\hline Search engine (eg, Google scholar) & $41(6.8)$ \\
\hline
\end{tabular}

items ranged from 4.5 to 75.8 . The overall agreement among reviewers for evaluation using the AMSTAR Checklist was moderate (ICC $=0.81 ; 95 \%$ CI 0.71 to 0.89). Six AMSTAR items $(1,2,3,4,5$ and 11) were reported in less than $50 \%$ of the total reports. No significant difference was found for the MAs published in journals cited by CSCD versus non-CSCD. Compared to studies published before 2010, there was an increase in seven items $(1,2,3,5,6,7$ and 10) on the AMSTAR checklist $(\mathrm{p}<0.05$; table 4$)$.

\section{MOOSE checklist (current edition) assessment}

Table 5 shows the proportion of all MAs reporting each item in the MOOSE checklist. Compliance with the MOOSE checklist items ranged from $0 \%$ to $96.7 \%$. The overall agreement among reviewers for evaluation with the MOOSE checklist was also moderate ( $\mathrm{ICC}=0.79$; $95 \%$ CI 0.68 to 0.87 ). Fourteen MOOSE checklist subitems $(2,5,6,7,8,9,12,13,14,15,16,20,29$ and 35) were mentioned in less than $50 \%$ of the total reports, and four of these subitems $(7,13,14$ and 16) were included in less than $10 \%$ of the reports. There was also no statistically significant difference in the source of journals cited by CSCD versus non-CSCD. In addition, the quality of reporting demonstrated significant improvement regarding the background (item 3), search strategy (items $7,8,9,10,12,14$ and 15), methods (items17, 18, 19, 20, 21, 22 and 24), results (items 25, 27 and 28) and discussion (items 30 and 31). However, no study provided the name and version of the search software employed (subitem 11), and there was no mention of the special features used (table 5).

\section{DISCUSSION}

Our study shows that large numbers of MAs of observational studies have recently been conducted, with 607 publications identified in Chinese journals. This study was the first to examine the compliance of Chinese observational study MAs using the MOOSE reporting guidelines and the AMSTAR tool for assessing methodological quality.

This study found that the methodological quality of Chinese MAs is poor. In particular, we found the retrievals were not comprehensive and lacked bias assessments in the majority of the MAs that we examined. Reporting the details of the search strategy is a requirement for MAs, as this information facilitates an assessment of comprehensiveness and ensures reproducibility. ${ }^{12}$ This study demonstrated that $85.8 \%$ of the MAs examined did not perform comprehensive literature searches; for example, only $14.3 \%$ of the studies presented their search strategy; $15.7 \%$ of the studies included searches of grey literature; and $67.7 \%$ of the studies used manual retrieval. Moreover, the lack of detailed retrieval strategies and qualifications of the searchers (ie, librarians and investigators) should also be noted. Ma et $a l^{13}$ reported that $59.1 \%$ of Chinese SRs of acupuncture 
Table 4 AMSTAR assessment of methodological characteristics $(n=607)$

\begin{tabular}{|c|c|c|c|c|c|c|c|c|c|c|}
\hline \multirow[b]{2}{*}{ Category } & \multicolumn{3}{|l|}{ Yes (\%) } & \multicolumn{3}{|c|}{ Partially/cannot tell (\%) } & \multicolumn{3}{|l|}{ No (\%) } & \multirow[b]{2}{*}{ p Values } \\
\hline & $\begin{array}{l}\text { All } \\
n=607\end{array}$ & $\begin{array}{l}\leq 2009 \\
n=230\end{array}$ & $\begin{array}{l}2010-2014 \\
n=377\end{array}$ & $\begin{array}{l}\text { All } \\
n=607\end{array}$ & $\begin{array}{l}\leq 2009 \\
n=230\end{array}$ & $\begin{array}{l}2010-2014 \\
n=377\end{array}$ & $\begin{array}{l}\text { All } \\
n=607\end{array}$ & $\begin{array}{l}\leq 2009 \\
n=230\end{array}$ & $\begin{array}{l}2010-2014 \\
n=377\end{array}$ & \\
\hline 1. Was an 'a priori' design provided? & $227(37.4)$ & $69(30.0)$ & $158(41.9)$ & $310(51.1)$ & $134(58.3)$ & 176 (46.7) & $70(11.5)$ & $27(11.7)$ & $43(11.4)$ & 0.010 \\
\hline $\begin{array}{l}\text { 2. Was there duplicate study selection and } \\
\text { data extraction? }\end{array}$ & $255(42.0)$ & $65(28.3)$ & $190(50.4)$ & $13(2.2)$ & $6(2.6)$ & $7(1.9)$ & $339(55.8)$ & $159(69.1)$ & $180(47.7)$ & 0.000 \\
\hline $\begin{array}{l}\text { 3. Was a comprehensive literature search } \\
\text { performed? }\end{array}$ & $86(14.2)$ & $22(9.6)$ & $64(16.9)$ & $392(64.6)$ & $141(61.3)$ & $251(66.6)$ & $129(21.2)$ & $67(29.1)$ & $62(16.5)$ & 0.000 \\
\hline $\begin{array}{l}\text { 4. Was the status of publication (ie, grey } \\
\text { literature) used as an inclusion criterion? }\end{array}$ & $95(15.7)$ & $37(16.1)$ & $58(15.4)$ & $0(0.0)$ & $0(0.0)$ & $0(0.0)$ & $512(84.3)$ & $193(83.9)$ & $319(84.6)$ & 0.817 \\
\hline $\begin{array}{l}\text { 5. Was a list of studies (included and } \\
\text { excluded) provided? }\end{array}$ & $63(10.4)$ & $20(8.7)$ & $43(11.4)$ & $96(15.8)$ & $50(21.7)$ & $46(12.2)$ & $448(73.8)$ & $160(69.6)$ & $288(76.4)$ & 0.006 \\
\hline $\begin{array}{l}\text { 6. Were the characteristics of the included } \\
\text { studies provided? }\end{array}$ & $460(75.8)$ & $158(68.7)$ & $302(80.1)$ & $12(1.9)$ & $6(2.6)$ & $6(1.6)$ & $135(22.3)$ & $66(28.7)$ & 69 (18.3) & 0.006 \\
\hline $\begin{array}{l}\text { 7. Was the scientific quality of the included } \\
\text { studies assessed and documented? }\end{array}$ & $317(52.2)$ & $96(41.7)$ & $221(58.6)$ & $0(0.0)$ & $0(0.0)$ & $0(0.0)$ & $290(47.8)$ & $134(58.3)$ & $156(41.4)$ & 0.000 \\
\hline $\begin{array}{l}\text { 8. Was the scientific quality of the included } \\
\text { studies used appropriately in formulating } \\
\text { conclusions? }\end{array}$ & $357(58.8)$ & $124(53.9)$ & $233(61.8)$ & $23(3.8)$ & 8 (3.5) & $15(3.9)$ & $227(37.4)$ & $98(42.6)$ & $129(34.3)$ & 0.117 \\
\hline $\begin{array}{l}\text { 9. Were the methods used to combine the } \\
\text { findings of studies appropriate? }\end{array}$ & $436(71.8)$ & 169 (73.5) & $267(70.8)$ & $150(24.7)$ & $54(23.5)$ & $97(25.7)$ & 21 (3.5) & $7(3.0)$ & $13(3.5)$ & 0.055 \\
\hline $\begin{array}{l}\text { 10. Was the likelihood of publication bias } \\
\text { assessed? }\end{array}$ & $374(61.6)$ & $110(47.8)$ & $264(70.0)$ & $11(1.8)$ & $6(2.6)$ & 5 (1.3) & $222(36.6)$ & $114(49.6)$ & $108(28.7)$ & 0.000 \\
\hline 11. Was the conflict of interest stated? & $27(4.5)$ & $8(3.5)$ & $19(5.0)$ & $0(0.0)$ & $0(0.0)$ & $0(0.0)$ & $580(95.5)$ & $222(96.5)$ & $358(95.0)$ & 0.356 \\
\hline
\end{tabular}


Table 5 MOOSE assessment of reporting characteristics $(n=607)$

\begin{tabular}{|c|c|c|c|c|c|c|c|c|c|c|}
\hline \multirow[b]{2}{*}{ Category } & \multicolumn{3}{|l|}{ Yes (\%) } & \multicolumn{3}{|c|}{ Partially/cannot tell (\%) } & \multicolumn{3}{|l|}{ No (\%) } & \multirow[b]{2}{*}{ p Values } \\
\hline & $\begin{array}{l}\text { All } \\
n=607\end{array}$ & $\begin{array}{l}\leq 2009 \\
n=230\end{array}$ & $\begin{array}{l}2010-2014 \\
n=377\end{array}$ & $\begin{array}{l}\text { All } \\
n=607\end{array}$ & $\begin{array}{l}\leq 2009 \\
\mathrm{n}=\mathbf{2 3 0}\end{array}$ & $\begin{array}{l}2010-2014 \\
n=377\end{array}$ & $\begin{array}{l}\text { All } \\
n=607\end{array}$ & $\begin{array}{l}\leq 2009 \\
n=230\end{array}$ & $\begin{array}{l}2010-2014 \\
n=377\end{array}$ & \\
\hline \multicolumn{11}{|l|}{ Reporting of background should include } \\
\hline 1. Problem definition & $536(88.3)$ & $198(86.1)$ & $338(89.7)$ & $28(4.6)$ & $14(6.1)$ & $14(3.7)$ & $43(7.1)$ & $18(7.8)$ & $25(6.6)$ & 0.080 \\
\hline 2. Hypothesis statement & $279(45.9)$ & $94(40.9)$ & $185(49.1)$ & $165(27.2)$ & $64(27.8)$ & $101(26.8)$ & $163(26.9)$ & $72(31.3)$ & $91(24.1)$ & 0.087 \\
\hline 3. Description of study outcome (s) & $376(61.9)$ & $129(56.1)$ & $247(65.5)$ & $79(13.0)$ & $45(19.6)$ & $34(9.1)$ & $152(25.1)$ & $56(24.3)$ & $96(25.4)$ & 0.001 \\
\hline $\begin{array}{l}\text { 4. Type of exposure or intervention } \\
\text { used }\end{array}$ & $430(70.9)$ & $154(66.9)$ & $276(73.2)$ & $2(0.3)$ & $0(0.0)$ & $2(0.5)$ & $175(28.8)$ & $76(33.1)$ & $99(26.3)$ & 0.117 \\
\hline 5. Type of study designs used & $202(33.3)$ & $70(30.4)$ & $132(35.1)$ & $0(0.0)$ & $0(0.0)$ & $0(0.0)$ & $405(66.7)$ & $160(69.5)$ & $245(64.9)$ & 0.246 \\
\hline 6. Study population & $234(38.6)$ & $86(37.4)$ & $148(39.3)$ & $0(0.0)$ & $0(0.0)$ & $0(0.0)$ & $373(61.4)$ & $144(62.6)$ & $229(60.7)$ & 0.647 \\
\hline \multicolumn{11}{|c|}{ Reporting of search strategy should include } \\
\hline $\begin{array}{l}\text { 7. Qualifications of searchers } \\
\text { (ie, librarians and investigators) }\end{array}$ & $12(1.9)$ & $1(0.4)$ & $11(2.9)$ & $0(0.0)$ & $0(0.0)$ & $0(0.0)$ & $595(98.1)$ & $229(99.6)$ & $366(97.1)$ & 0.033 \\
\hline $\begin{array}{l}\text { 8. Search strategy, including time period } \\
\text { included in the synthesis and } \\
\text { keywords }\end{array}$ & $167(27.5)$ & $38(16.5)$ & $129(34.2)$ & $396(65.2)$ & $167(72.6)$ & $229(60.7)$ & $44(7.3)$ & $25(10.9)$ & $19(5.1)$ & 0.000 \\
\hline $\begin{array}{l}\text { 9. Effort to include all available studies, } \\
\text { including contact with authors }\end{array}$ & $212(34.9)$ & $53(23.1)$ & $159(42.2)$ & $0(0.0)$ & $0(0.0)$ & $0(0.0)$ & $395(65.1)$ & $177(76.9)$ & $218(57.8)$ & 0.000 \\
\hline 10. Databases and registries searched & $401(66.1)$ & $134(58.3)$ & $267(70.8)$ & $177(29.2)$ & 78 (33.9) & $99(26.3)$ & $29(4.7)$ & $18(7.8)$ & $11(2.9)$ & 0.001 \\
\hline $\begin{array}{l}\text { 11. Search software used, name and } \\
\text { version, including special features } \\
\text { used (ie, explosion) }\end{array}$ & $0(0.0)$ & $0(0.0)$ & $0(0.0)$ & $0(0.0)$ & $0(0.0)$ & $0(0.0)$ & $607(100.0)$ & $230(100.0)$ & $377(100.0)$ & 1 \\
\hline $\begin{array}{l}\text { 12. Use of manual searching (ie, } \\
\text { reference lists of obtained articles) }\end{array}$ & $125(20.6)$ & $36(15.7)$ & $89(23.6)$ & $0(0.0)$ & $0(0.0)$ & $0(0.0)$ & $482(79.4)$ & $194(84.3)$ & $288(76.4)$ & 0.019 \\
\hline $\begin{array}{l}\text { 13. List of citations located and those } \\
\text { excluded, including justification }\end{array}$ & $43(7.1)$ & $12(5.2)$ & $31(8.2)$ & $57(9.4)$ & $20(8.7)$ & $37(9.8)$ & $507(83.5)$ & $198(86.1)$ & $309(82.0)$ & 0.060 \\
\hline $\begin{array}{l}\text { 14. Method of addressing articles } \\
\text { published in languages other than } \\
\text { English }\end{array}$ & $21(3.5)$ & $2(0.9)$ & $19(5.1)$ & $0(0.0)$ & $0(0.0)$ & $0(0.0)$ & $586(96.5)$ & $228(99.1)$ & $358(94.9)$ & 0.006 \\
\hline $\begin{array}{l}\text { 15. Method of handling abstracts and } \\
\text { unpublished studies }\end{array}$ & $110(18.1)$ & 25 (10.9) & $85(22.5)$ & $89(14.7)$ & $10(4.3)$ & $79(20.9)$ & $408(67.2)$ & $195(84.8)$ & $213(56.4)$ & 0.000 \\
\hline $\begin{array}{l}\text { 16. Description of any contact with } \\
\text { authors }\end{array}$ & $26(4.3)$ & $9(3.9)$ & $17(4.5)$ & $0(0.0)$ & $0(0.0)$ & $0(0.0)$ & $581(95.7)$ & $221(96.1)$ & $360(95.5)$ & 0.725 \\
\hline \multicolumn{11}{|l|}{ Reporting of methods should include } \\
\hline $\begin{array}{l}\text { 17. Description of relevance or } \\
\text { appropriateness of studies } \\
\text { assembled for assessing the } \\
\text { hypothesis to be tested }\end{array}$ & $427(70.3)$ & $148(64.3)$ & $279(74.1)$ & $0(0.0)$ & $0(0.0)$ & $0(0.0)$ & $180(29.7)$ & $82(35.7)$ & $98(25.9)$ & 0.011 \\
\hline $\begin{array}{l}\text { 18. Rationale for the selection and } \\
\text { coding of data (ie, sound clinical } \\
\text { principles or convenience) }\end{array}$ & $430(70.8)$ & $149(64.8)$ & $281(74.5)$ & $0(0.0)$ & $0(0.0)$ & $0(0.0)$ & 177 (29.2) & $81(35.2)$ & $96(25.5)$ & 0.010 \\
\hline
\end{tabular}




\section{Category}

19. Documentation of how data were classified and coded (ie, multiple raters, blinding and inter-rater reliability)

20. Assessment of confounding (ie, comparability of cases and controls in studies where appropriate)

21. Assessment of study quality, including blinding of quality assessors; stratification or regression on possible predictors of study results

22. Assessment of heterogeneity

23. Description of statistical methods

(ie, complete description of fixed or random effects models, justification of whether the chosen models account for predictors of study results, dose-response models, or cumulative meta-analysis) in sufficient detail to be replicated

24. Provision of appropriate tables and graphics

Reporting of results should include

25. Graphic summarising individual study estimates and overall estimate

26. Table giving descriptive information for each study included

27. Results of sensitivity testing (ie, subgroup analysis)

28. Indication of statistical uncertainty of findings

Reporting of discussion should include

29. Quantitative assessment of bias (ie, publication bias)

30. Justification for exclusion (ie, exclusion of non-English-language citations)

\begin{tabular}{|c|c|c|c|c|c|c|c|c|c|}
\hline \multicolumn{3}{|l|}{ Yes (\%) } & \multicolumn{3}{|c|}{ Partially/cannot tell (\%) } & \multicolumn{3}{|l|}{ No (\%) } & \multirow[b]{2}{*}{ p Values } \\
\hline $\begin{array}{l}\text { All } \\
n=607\end{array}$ & $\begin{array}{l}\leq 2009 \\
n=230\end{array}$ & $\begin{array}{l}2010-2014 \\
n=377\end{array}$ & $\begin{array}{l}\text { All } \\
n=607\end{array}$ & $\begin{array}{l}\leq 2009 \\
n=230\end{array}$ & $\begin{array}{l}2010-2014 \\
n=377\end{array}$ & $\begin{array}{l}\text { All } \\
n=607\end{array}$ & $\begin{array}{l}\leq 2009 \\
n=230\end{array}$ & $\begin{array}{l}2010-2014 \\
n=377\end{array}$ & \\
\hline $405(66.7)$ & $136(59.1)$ & $269(71.4)$ & $0(0.0)$ & $0(0.0)$ & $0(0.0)$ & 202 (33.3) & $94(40.9)$ & $108(28.6)$ & 0.002 \\
\hline $288(47.5)$ & 95 (41.3) & $193(51.2)$ & $114(18.8)$ & $42(18.3)$ & $72(19.1)$ & 205 (33.7) & $93(40.4)$ & $112(29.7)$ & 0.020 \\
\hline $413(68.1)$ & $145(63.1)$ & $268(71.1)$ & $0(0.0)$ & $0(0.0)$ & $0(0.0)$ & $194(31.9)$ & 85 (36.9) & 109 (28.9) & 0.039 \\
\hline $355(58.5)$ & $102(44.3)$ & $253(67.1)$ & $200(32.9)$ & $110(47.8)$ & $90(23.8)$ & $52(8.6)$ & $18(7.9)$ & $34(9.1)$ & 0.000 \\
\hline 305 (50.2) & 108 (46.9) & 197 (52.3) & 250 (41.2) & $100(43.5)$ & $150(39.8)$ & $52(8.6)$ & $22(9.6)$ & $30(7.9)$ & 0.427 \\
\hline $537(88.5)$ & $195(84.8)$ & $342(90.7)$ & $0(0.0)$ & $0(0.0)$ & $0(0.0)$ & $70(11.5)$ & $35(15.2)$ & $35(9.3)$ & 0.026 \\
\hline $310(51.1)$ & 78 (33.9) & $232(61.5)$ & $107(17.6)$ & $51(22.2)$ & $56(14.9)$ & 190 (31.3) & 101 (43.9) & 89 (23.6) & 0.000 \\
\hline 305 (50.2) & $110(47.8)$ & $195(51.7)$ & $140(23.1)$ & $57(24.8)$ & $83(22.1)$ & $63(27.4)$ & 99 (26.2) & $112(29.6)$ & 0.098 \\
\hline $442(72.8)$ & $152(66.1)$ & 290 (76.9) & $0(0.0)$ & $0(0.0)$ & $0(0.0)$ & $165(27.2)$ & 78 (33.9) & $87(23.1)$ & 0.004 \\
\hline 587 (96.7) & 217 (94.3) & $370(98.1)$ & $0(0.0)$ & $0(0.0)$ & $0(0.0)$ & $20(3.3)$ & $13(5.7)$ & 7 (1.9) & 0.011 \\
\hline $246(40.5)$ & $91(39.6)$ & $155(41.1)$ & $107(17.6)$ & $41(17.8)$ & $66(17.5)$ & $254(41.9)$ & $98(42.6)$ & $156(41.4)$ & 0.930 \\
\hline 307 (50.6) & $59(25.7)$ & $248(65.8)$ & $0(0.0)$ & $0(0.0)$ & $0(0.0)$ & 300 (49.4) & $171(74.3)$ & $129(34.2)$ & 0.000 \\
\hline
\end{tabular}

Continued 


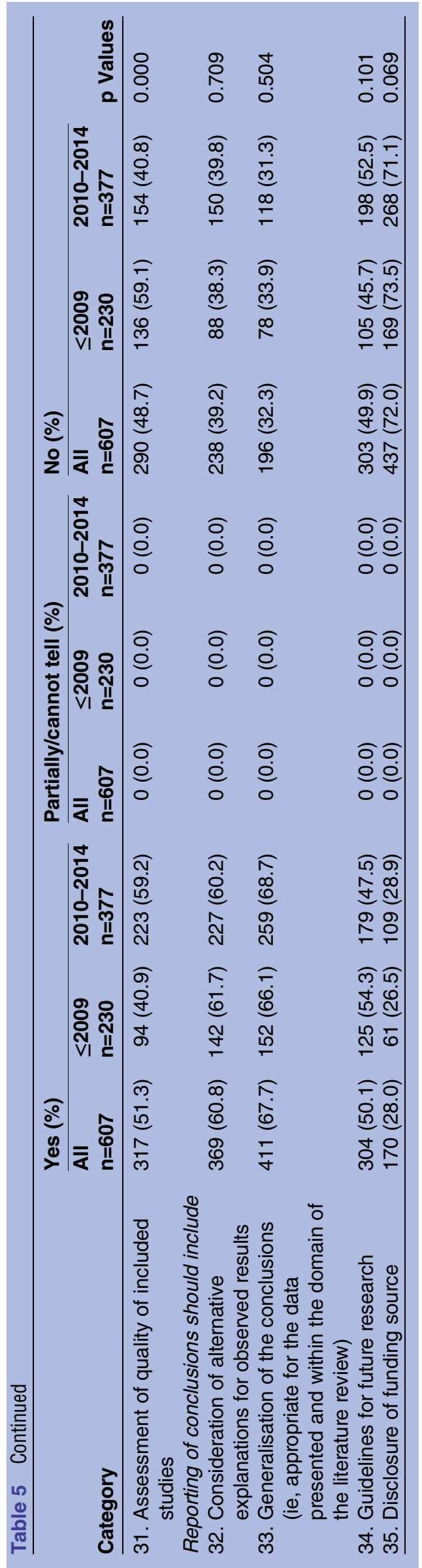

interventions published in Chinese journals did not perform comprehensive literature searches and that $97.7 \%$ did not include searches of grey literature or ongoing studies. Moreover, the lack of a comprehensive search was clearly the weakest item in the identified MAs in Chinese journals.

Risk of bias is important because poor methodological quality can lead to a biased estimate. In the present research, nearly one-half of the studies did not mention how the quality of included primary studies was assessed. In addition, 29 (4.8\%) studies used the STROBE criteria. However, it should be noted that the STROBE criteria were not developed as a tool for assessing the quality of published observational studies; instead, the STROBE criteria were developed solely to provide guidance on how to report observational research. ${ }^{14}$ Similarly, Bruno et al ${ }^{15}$ reported that about half of the systematic reviews and meta-analyses used STROBE inappropriately, as a methodological quality assessment tool. In some instances, specific checklists for observational studies were used, including the NOS and CASP, which have been shown to be generally useful for assessing the quality of nonrandomised studies despite some limitations. ${ }^{16}{ }^{17}$ These assessments serve to identify the strengths and limitations of included studies, including the quality of strength of the evidence for a given outcome. The NOS has been endorsed for use in systematic reviews of non-randomised studies by the Cochrane Collaboration, specifically for cohort and case-control studies. CASP is an instrument for the appraisal of systematic reviews based on 10 questions for addressing the key components of methodological quality. Therefore, to obtain valuable findings from observational study MAs, adequate assessment based on the correct study design is essential.

In addition, many studies did not report key aspects of MAs methodologies, which reduces confidence in the results and impairs the conclusion. For example, more than half of the studies reported an 'a priori' design, and another $11.5 \%$ of the studies did not reveal their design information. The most common means of assessing publication bias was by funnel plot, and more than one-third of the studies did not consider or assess publication bias despite considerable evidence for its existence and its potential influence on the MA results. Only $4.5 \%$ of the studies stated conflicts of interest; for example, Barnes and Bero $^{18}$ reported that funding sources may have influenced the outcomes and quality of the research. These important methodology components must be considered in future research.

Accurate reporting is essential to maintain a clear scientific record, which can then be used for the synthesis of existing evidence, clinical decision-making and health policy determination. Groenwold et $a l^{19}$ reported that the quality of reporting on confounding in observational studies was rather poor, even in high-impact general medical journals. Our studies showed that less than $50 \%$ of the included studies assessed confounding. As it cannot be guaranteed that known and unknown 
confounding factors are distributed equally among the observation groups, results of this type are susceptible to distortions. Therefore, clinicians reading the reports of MAs must be able to appraise the method and validity of the study to confidently interpret the results.

As mentioned above, we found that the quality of reporting regarding search strategies and methods significantly improved after publication of the MOOSE checklist. However, this observation is prone to many biases and could simply represent improvements in research methods over time. Nonetheless, room for improvement still exists. For example, approximately one-half of the studies did not present risk bias assessment results, which could have affected the cumulative evidence. This is despite the fact that many studies have previously shown the importance of assessing bias heterogeneity across studies. ${ }^{20}{ }^{21}$ Disappointingly, $41.2 \%$ of the studies did not describe the statistical methods in sufficient detail; in fact, some of the studies did not explore the reasons for statistical heterogeneity and simply pooled results using a random effects model to account for heterogeneity. These shortcomings may have led to incorrect or inappropriate interpretations of the results.

Panic et $a l^{22}$ reported that the endorsement of PRISMA resulted in increase of both quality of reporting and methodological quality. Our studies showed that less than one-fifth of the included studies were indexed in the Chinese Science Citation Database (CSCD), which is similar to the Science Citation Index. The reason may be the overall poor quality of work and many deficits in reporting in the same field in the Chinese MAs. Therefore, broader promotion of methodological quality guidelines is a necessary step in enhancing dissemination and implementation of AMSTAR and MOOSE.

The strengths of this study include its comprehensive literature search using five Chinese databases, to ensure a high degree of representativeness. In addition, both the eligibility process and data extraction were conducted by two independent investigators, with a third investigator providing quality evaluation. Nonetheless, there were some limitations in our current study. First, in this study, the terms 'meta-analysis', 'systematic review' and 'pooled analysis' were used, although some potentially eligible MAs may not have included these terms in their publications. Second, this study included only MAs published in Chinese journals, whereas Chinese investigators increasingly publish articles in international journals. Third, our studies relied on reporting from authors, and it is possible that the authors may have omitted important details from their reports or that the peer-review process resulted in the removal of key information from these reviews.

\section{CONCLUSION}

The goal of the present study was to provide readers with a broad overview of the reporting and methodological characteristics of published Chinese observational study MAs. Although many such MAs have been published, the quality of these MAs is troubling. Thus, the reporting guidelines and methodological tools should be used to improve the quality of future MAs.

Author affiliations

${ }^{1}$ School of Basic Medical Sciences, Lanzhou University, Lanzhou, China

${ }^{2}$ The First Hospital of Lanzhou University, Lanzhou, China

${ }^{3}$ The First School of Clinical Medicine of Lanzhou University, Lanzhou, China

${ }^{4}$ Evidence-Based Medicine Center, Institute of Traditional Chinese and Western Medicine, School of Basic Medical Sciences, Lanzhou University, Lanzhou, China

Contributors Z-wZ and H-hY contributed to the design and implementation of the study. Z-wZ and JC searched the literature. ZL, J-cM, J-IL and JW participated in data extraction and quality assessment of the MAs, with guidance from K-hY. All the authors participated in data interpretation. Z-wZ and $\mathrm{K}$-hY wrote the first draft of the report and all the other authors commented on the draft and approved the final version.

Funding This research received no specific grant from any funding agency in the public, commercial or not-for-profit sectors.

Competing interests None declared.

Provenance and peer review Not commissioned; externally peer reviewed.

Data sharing statement No additional data are available.

Open Access This is an Open Access article distributed in accordance with the Creative Commons Attribution Non Commercial (CC BY-NC 4.0) license, which permits others to distribute, remix, adapt, build upon this work noncommercially, and license their derivative works on different terms, provided the original work is properly cited and the use is non-commercial. See: http:// creativecommons.org/licenses/by-nc/4.0/

\section{REFERENCES}

1. Booth $A$, Clarke $M$, Ghersi $D$, et al. An international registry of systematic-review protocols. Lancet 2011;377:108-9.

2. Samaan Z, Mbuagbaw L, Kosa D, et al. A systematic scoping review of adherence to reporting guidelines in health care literature. $J$ of Multidiscip Healthc 2013;6:169-88.

3. Mundi R, Chaudhry $\mathrm{H}$, Singh I, et al. Checklists to improve the quality of the orthopaedic literature. Indian J Orthop 2008;42:150-64.

4. Sporbeck B, Jacobs A, Hartmann V, et al. Methodological standards in medical reporting. J Dtsch Dermatol Ges 2013;11:107-20.

5. Langan S, Schmitt J, Coenraads PJ, et al. The reporting of observational research studies in dermatology journals: a literature-based study. Arch Dermatol 2010;146:534-41.

6. Zhan SY. How to report systematic reviews and meta-analysis: introduction of QUOROM and MOOSE. Chin J Evid Based Pediatr 2010;5:60-3.

7. Xiong L, Du YH. Assessing tool of methodology quality for systematic reviews and meta-analysis: introduction of AMSTAR. Chin J Evid Based Med 2010;9:44.

8. Junhua, Z Hongcai, S Xiumei, G, et al. Methodology and reporting quality of systematic review/meta-analysis of traditional Chinese medicine. J Altern Complement Med 2007;13:797-805.

9. Ma B, Ke FY, Chen ZM, et al. Does the reporting of randomized clinical trials published in Chinese pediatrics journals improve after the CONSORT Statement is adopted? Contemp Clin Trials 2012;33:889-94.

10. Su N, Lü̆J, Li C, et al. Assessment of reliability and validity of assessment of multiple systematic reviews in Chinese systematic reviews on stomatology. Hua Xi Kou Qiang Yi Xue Za Zhi 2013;31:49-52.

11. Shrout PE, Fleiss JL. Intraclass correlations: uses in assessing rater reliability. Psychol Bull 1979;86:420-8.

12. Delaney A, Bagshaw SM, Ferland A, et al. A systematic evaluation of the quality of meta-analyses in the critical care literature. Crit Care 2005;9:R575-82.

13. Ma B, Guo J, Qi G, et al. Epidemiology, quality and reporting characteristics of systematic reviews of traditional Chinese medicine interventions published in Chinese journals. PLOS ONE 2011;6: e20185. 
14. von Elm E, Altman DG, Egger M, et al. The Strengthening the Reporting of Observational Studies in Epidemiology (STROBE) statement: guidelines for reporting observational studies. J Clin Epidemiol 2008:61:344-9.

15. da Costa BR, Cevallos M, Altman DG, et al. Uses and misuses of the STROBE statement: bibliographic study. BMJ Open 2011;1: e000048.

16. Wells G, Shea B, O'Connell D, et al. The Newcastle-Ottawa Scale (NOS) for assessing the quality of nonrandomized studies in meta-analysis. Ottawa: University of Ottawa, 2008. http://www.ohri. $\mathrm{ca} /$ programs/clinical-epidemiology/oxford-web.ppt

17. Critical Skills Appraisal Program (CASP) [EB/OL]. 2012. http://www. casp-uk.net/wp-content/uploads/2011/11/CASP-Cohort-AppraisalChecklist-14oct10.pdf
18. Barnes DE, Bero LA. Why review article on health effects of passive smoking reach different conclusions. JAMA 1998;279:1566-70.

19. Groenwold RHH, Van Deursen AMM, Hoes AW, et al. Poor quality of reporting confounding bias in observational intervention studies: a systematic review. Ann Epidemiol 2008;18:746-51.

20. Thompson SG. Systematic review: why sources of heterogeneity in meta-analysis should be investigated. BMJ 1994;309:1351-5.

21. Papathanasiou AA, Zintzaras E. Assessing the quality of reporting of observational studies in cancer. Ann Epidemiol 2010;20:67-73.

22. Panic N, Leoncini $\mathrm{E}$, de Belvis $\mathrm{G}$, et al. Evaluation of the endorsement of the Preferred Reporting Items for Systematic Reviews and Meta-Analysis (PRISMA) statement on the quality of published systematic review and meta-analyses. PLOS ONE 2013;8: e83138. 